\title{
Are outpatient total hip and knee arthroplasties safe?
}

\author{
O. Şahap Atik, MD'1D, Cemil Ertürk, MD² (D) \\ ${ }^{1}$ President, Turkish Joint Diseases Foundation, Ankara, Turkey \\ ${ }^{2}$ Department of Orthopedics and Traumatology, Health Sciences University, Istanbul Kanuni Sultan Süleyman Training and \\ Research Hospital, Istanbul, Turkey
}

Total hip and knee arthroplasties are definitive management for end-stage osteoarthritis and avascular necrosis. ${ }^{[1]}$ Until recently, total hip and knee arthroplasties were listed as Inpatient Only (IPO) procedures by the United States Centers for Medicare \& Medicaid Services (CMS), which requires greater than $24 \mathrm{~h}$ of postoperative care. ${ }^{[2]}$ These procedures represent a significant economic burden on the healthcare systems, which are expected to increase, as the population ages.

Fast-track surgery was introduced in the early 1990s, but implementation of this concept in clinical orthopedic practice has been slow. ${ }^{[3]}$ Arthroplasty articles submitted to our journal from European countries are only inpatient reports. ${ }^{[4-9]}$ However, outpatient arthroplasty has gained popularity over time, as the fast-track concept has evolved with perioperative treatment with rapid recovery protocols, leading to enhanced recovery after surgery and reduced length of hospital stay and cost.

Received: November 18, 2020

Accepted: November 21, 2020

Published online: January 06, 2021

Correspondence: O. Sahap Atik, MD. Turkish Joint Diseases

Foundation, Mustafa Kemal Mah., Dumlupınar Bul., 274/2

C2 Blok, Ofis 5, 06900 Çankaya, Ankara, Türkiye.

E-mail: satikmd@gmail.com

Doi: $10.5606 /$ ehc. 2020.57898

Citation: Atik OŞ, Ertürk C. Are outpatient total hip and knee arthroplasties safe? Jt Dis Relat Surg 2021;32(1):1-2.

02021 All right reserved by the Turkish Joint Diseases Foundation

This is an open access article under the terms of the Creative Commons Attribution-NonCommercial License, which permits use, distribution and reproduction in any medium, provided the original work is properly cited and is not used for commercial purposes (http://creativecommons.org/licenses/by-nc/4.0/)
The CMS removed total knee arthroplasty from the IPO list in 2018 with the expectation of reducing healthcare cost. ${ }^{[2]}$

On the other hand, there are still safety concerns regarding complications and readmissions. Nationwide data from a private insurance database in the US demonstrated a higher risk of perioperative surgical and medical complications including surgical site infection, rehabilitation, and deep vein thrombosis. ${ }^{[10]} \mathrm{A}$ meta-analysis documented that outpatient total knee arthroplasties led to an increased number of complications, although there were no significant differences in the number of readmissions. ${ }^{[11]}$ In another study, although same day discharge after total hip and knee arthroplasties was not associated with the increased risk of unplanned readmission, these patients had an increased risk of cardiac/pulmonary complications within 30 days following surgery. ${ }^{[2]}$

Independent risk factors for developing a complication or requiring an inpatient stay include general anesthesia, a body mass index of $>35 \mathrm{~kg} / \mathrm{m}^{2}$, diabetes, chronic obstructive pulmonary disease, congestive heart failure, hypertension, malnutrition, female sex, age $>75$ years, minority ethnicity, and an American Society of Anesthesiologists Class IV. ${ }^{[12]}$ Of note, whether outpatient arthroplasty is worth considering still remains to be elucidated, except in very exceptional cases (i.e., young patients without associated comorbidities). ${ }^{[13]}$

In conclusion, we still need more information regarding patient selection criteria, preoperative medical optimization, and perioperative treatment protocols for implementing successful outpatient arthroplasty. Therefore, further studies are required to investigate complications following outpatient arthroplasties in well-selected patient populations. 


\section{REFERENCES}

1. Zhou M, Liu L, Xu Y, Jiang J, Liu G, Zhai C. Effects of osteoblast autophagy on glucocorticoid-induced femoral head necrosis. Jt Dis Relat Surg 2020;31:411-8.

2. Liu J, Elkassabany N, Poeran J, Gonzalez Della Valle A, Kim DH, Maalouf D, et al. Association between same day discharge total knee and total hip arthroplasty and risks of cardiac/pulmonary complications and readmission: a population-based observational study. BMJ Open 2019;9:e031260.

3. Kehlet H. Fast-track hip and knee arthroplasty. Lancet 2013;381:1600-2.

4. Levent A, Köse Ö, Linke P, Gehrke T, Çıtak M. Does tourniquet use decrease blood loss following primary total knee arthroplasty in Jehovah's Witness patients? Jt Dis Relat Surg 2020;31:419-25.

5. Lacko M, Jarčuška P, Schreierova D, Lacková A, Gharaibeh A. Tranexamic acid decreases the risk of revision for acute and delayed periprosthetic joint infection after total knee replacement. Jt Dis Relat Surg 2020;31:8-13.

6. Papp M, Zsákai Z, Gömöri A. Comparison of total knee arthroplasty after combined high tibial osteotomy with a matched group of primary total knee arthroplasty. Eklem Hastalik Cerrahisi 2019;30:79-84.

7. Sever GB, Cankuş C. The long-term results of cemented Oxford unicompartmental knee arthroplasty: A single- center experience. Eklem Hastalik Cerrahisi 2019;30:233-40.

8. Çağlar Ö, Tokgözoğlu M, Akgün RC, Atilla B. Lowdose vancomycin-loaded cement spacer for two-stage revision of infected total hip arthroplasty. Jt Dis Relat Surg 2020;31:449-55.

9. Ertilav D, Cavit A, Bilbaşar H, Ürgüden M. Stepped osteotomy of femoral head autograft for acetabular reconstruction in total hip arthroplasty for dysplasia of the hip: 3 to 12 years' results. Jt Dis Relat Surg 2020;31:353-9.

10. Arshi A, Leong NL, D'Oro A, Wang C, Buser Z, Wang JC, et al. Outpatient Total Knee Arthroplasty Is Associated with Higher Risk of Perioperative Complications. J Bone Joint Surg Am 2017;99:1978-86.

11. Bordoni V, Poggi A, Zaffagnini S, Previtali D, Filardo G, Candrian C. Outpatient total knee arthroplasty leads to a higher number of complications: a meta-analysis. J Orthop Surg Res 2020;15:408.

12. Greenky MR, Wang W, Ponzio DY, Courtney PM. Total Hip Arthroplasty and the Medicare Inpatient-Only List: An Analysis of Complications in Medicare-Aged Patients Undergoing Outpatient Surgery. J Arthroplasty 2019;34:1250-4.

13. Rodríguez-Merchán EC. Outpatient total knee arthroplasty: is it worth considering? EFORT Open Rev 2020;5:172-9. 